ИЗВЕСТИЯ АКАДЕМИИ НАУК ЭСТОНСКОИ ССР. ТОМ ІХ СЕРИЯ ФИЗИКО-МАТЕМАТИЧЕСКИХ И ТЕХНИЧЕСКИХ НАУК, 1960, № 4

\title{
ВЛИЯНИЕ УСЛОВИИ НАГРЕВА НА РАСПРЕДЕЛЕНИЕ ПРОДУКТОВ ПРИ ТЕРМИЧЕСКОМ РАЗЛОЖЕНИИ СЛАНЦА- КУКЕРСИТА
}

\author{
М. Я. ГУБЕРГРИЦ, \\ кандидат технических наук
}

Применение современных физико-химических методов исследования позволяет во многом дополнить и уточнить существующие представления о влиянии условий нагрева на распределение и формирование летучих веществ и твердого остатка при термическом разложении сланца-кукерсита. В настоящей статье в сжатом виде излагаются и обобшаются результаты проведенного с этой целью комплексного исследования процесса термического разложения зернистого сланца при скоростном нагреве, соответствующем различным режимам переработки этого топлива (в частности - в установках с твердым теплоносителем).

\section{Методика комплексного экспериментального исследования}

Нагрев зернистого сланца с заданной скоростью осуществлен в плоском металлическом реакторе, помещенном в печь с программным регулятором. Конструкция реактора обеспечивает равномерный по объему прогрев загрузки (100 г) и небольшую продолжительность контакта летучих с твердым материалом, что ограничивает искажающее действие вторичных реакций в парогазовой фазе [']. В опытах серий $1-3$ по достижении заданной температуры (в диапазоне от 450 до $800^{\circ}$ через каждые 50 $100^{\circ}$ и при скоростях нагрева 14,28 и $75^{\circ} \mathrm{C} /$ мин) производится пятнадцатиминутная изотермическая выдержка с последующим быстрым охлаждением до $300^{\circ}$. Опыты серии 4 проведены при скорости нагрева $v_{\text {н }}=14^{\circ} \mathrm{C} /$ мин в интервале значений температуры выдержки $t_{\text {в }}$ от 280 до $520^{\circ}$ при различной ее продолжительности $\tau_{\mathrm{B}}$. Материальный баланс для каждого эксперимента составлен из расчета на исходные сланец и кероген, а также по элементам (C, H, O $+\mathrm{N}, \mathrm{S})$ с невязкой не более $2-4 \%$.

Исследование состава газа произведено с помощью специально сконструированного хромотермографа, позволяющего определить концентрацию индивидуальных углеводородов с 1-4 атомами углерода в молекуле и, совместно с бутиленом, суммы углеводородов $\mathrm{C}_{5}$. В дополнение к элементарному анализу смолы для последней определены содержание кислых компонентов (объемным методом) и функциональных групп, удельный и молекулярный вес, а также подсчитана условная средняя степень конденсации молекул [2]. Для твердого остатка наряду с элементарным и техническим анализом в пробах из опытов серий $1-3$ проведено исследование структурных и физико-механических свойств с определением коэффициентов пористости и прочности $\left[{ }^{3,4}\right]$.

Средние пробы твердого остатка из опытов серии 4, измельченные под сито № 100 , подвергнуты радиоспектроскопическому исследованию. Производные спектров элекгронного парамагнитного резонанса (э.п.р.) сняты на приборе чувствительностью 
до $10^{14}$ спинов (калибровка по ДФПГ) при автоматической записи на потенциометре ЭПП-09 [5]. После извлечения спирт-бензолом так называемого термобитума в некоторых случаях для последнего также сняты спектры э.п.р. при двукратном разведении бензолом. Для твердого остатка определены также величины удельного электросопротивления @ по методике, описанной в работе [].*

Сырьем для исследования в сериях $1-3$ служил сланец из пласта В шахты «Кивиыли» с содержанием органического вещества $O^{c}=55,3 \%$, дробленный до класса крупности 10-15 мм при влагосодержании около $1,3 \%$; в серии 4 - смесь сланца из слоев A-E с $O c=38,45 \%$ и крупностью частиц 3-5 мм. Указанные различия в размерах зерен практически не отражаются на выходе и распределении продуктов полукоксования [?].

\section{РАСПРЕДЕЛЕНИЕ ЛЕТУЧИХ ПРОДУКТОВ В ЗАВИСИМОСТИ ОТ УСЛОВИИ НАГРЕВА}

\section{Влияние температурного потенциала}

Әкспериментальные данные по выходу и распределению летучих продуктов в зависимости от условий нагрева представлены в табл. 1 и 2. Приведенные результаты исследования показывают, что каждой данной скорости нагрева соответствует некоторое «критическое» значение температурного потенциала $t_{\text {кр }}$, при котором достигается предельно высокий выход летучих. Этому явлению соответствует и максимальный выход газообразных углеводородов (табл. 2) с преобладанием парафинов и, в частности, метана. Выход олефинов при критической температуре несколько снижается по сравнению с достигнутым на предыдущей ступени (за исключением серии 3 ).

Таблица 1

Распределение летучих в зависимости от условий нагрева (вес. \%)

\begin{tabular}{|c|c|c|c|c|c|c|c|c|c|c|c|c|c|c|}
\hline \multicolumn{15}{|c|}{ Распределение } \\
\hline \multicolumn{5}{|c|}{ 1. $v_{\mathrm{H}}=14^{\circ} \mathrm{C} / \mathrm{Mин}$} & \multicolumn{5}{|c|}{ 2. $v_{\mathrm{H}}=28^{\circ} \mathrm{C} / \mathrm{мин}$} & \multicolumn{5}{|c|}{ 3. $v_{\text {н }}=75^{\circ} \mathrm{C} /$ мин } \\
\hline \multirow{2}{*}{$\begin{array}{l}t_{\mathrm{B}}, \\
{ }^{\circ} \mathrm{C}\end{array}$} & \multicolumn{2}{|c|}{$\begin{array}{l}\text { Выход от } \\
\text { керогена }\end{array}$} & \multicolumn{2}{|c|}{$\begin{array}{l}\text { Выход от } \\
\text { суммы } \\
\text { летучих }\end{array}$} & \multirow{2}{*}{$\begin{array}{l}t_{\mathrm{B}}, \\
{ }^{\circ} \mathrm{C}\end{array}$} & \multicolumn{2}{|c|}{$\begin{array}{l}\text { Выход от } \\
\text { керогена }\end{array}$} & \multicolumn{2}{|c|}{$\begin{array}{c}\text { Выход от } \\
\text { суммы } \\
\text { летучих }\end{array}$} & \multirow{2}{*}{$\begin{array}{l}t_{\mathrm{B}}, \\
{ }^{\circ} \mathrm{C}\end{array}$} & \multicolumn{2}{|c|}{$\begin{array}{c}\text { Выход от } \\
\text { керогена }\end{array}$} & \multicolumn{2}{|c|}{$\begin{array}{c}\text { Выход or } \\
\text { суммы } \\
\text { летучих }\end{array}$} \\
\hline & 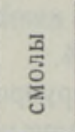 & 䒺离 & 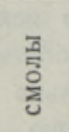 & 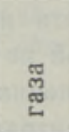 & & 롤 & 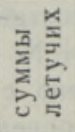 & है & 莽 & & 졸 & 产美 & $\frac{\overline{3}}{5}$ & 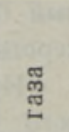 \\
\hline 450 & & & & & & & & & & 45 & & 6 & & 4,3 \\
\hline & & & 78 & 14 & & & & & & 5 & & & & 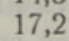 \\
\hline & & & & & & & & & & & & & & 17 \\
\hline & & & & 17 & & & & & & 6 & & & & \\
\hline & & 86 & 75 & 18 & 7 & 6 & 8 & 7 & & 72 & & & & 17 \\
\hline & & 87,6 & 73,0 & 20,4 & 820 & 63,9 & 87,9 & 72,6 & 20,5 & 770 & 65,3 & 87,7 & 74,5 & 19 , \\
\hline
\end{tabular}

* Описанный раздел работы проведен совместно с лабораторией радиационной химин Института нефтехимического сннтеза Академин наук СССР (руководитель проф. Л. С. Полак); остальные разделы экспериментального исследовання выполнены под руководством автора кандидатами технических наук Л. П. Паальме и Б. Х. Бродской, научными сотрудниками М. А. Маргусте и К. А. Куйвом. 
ป

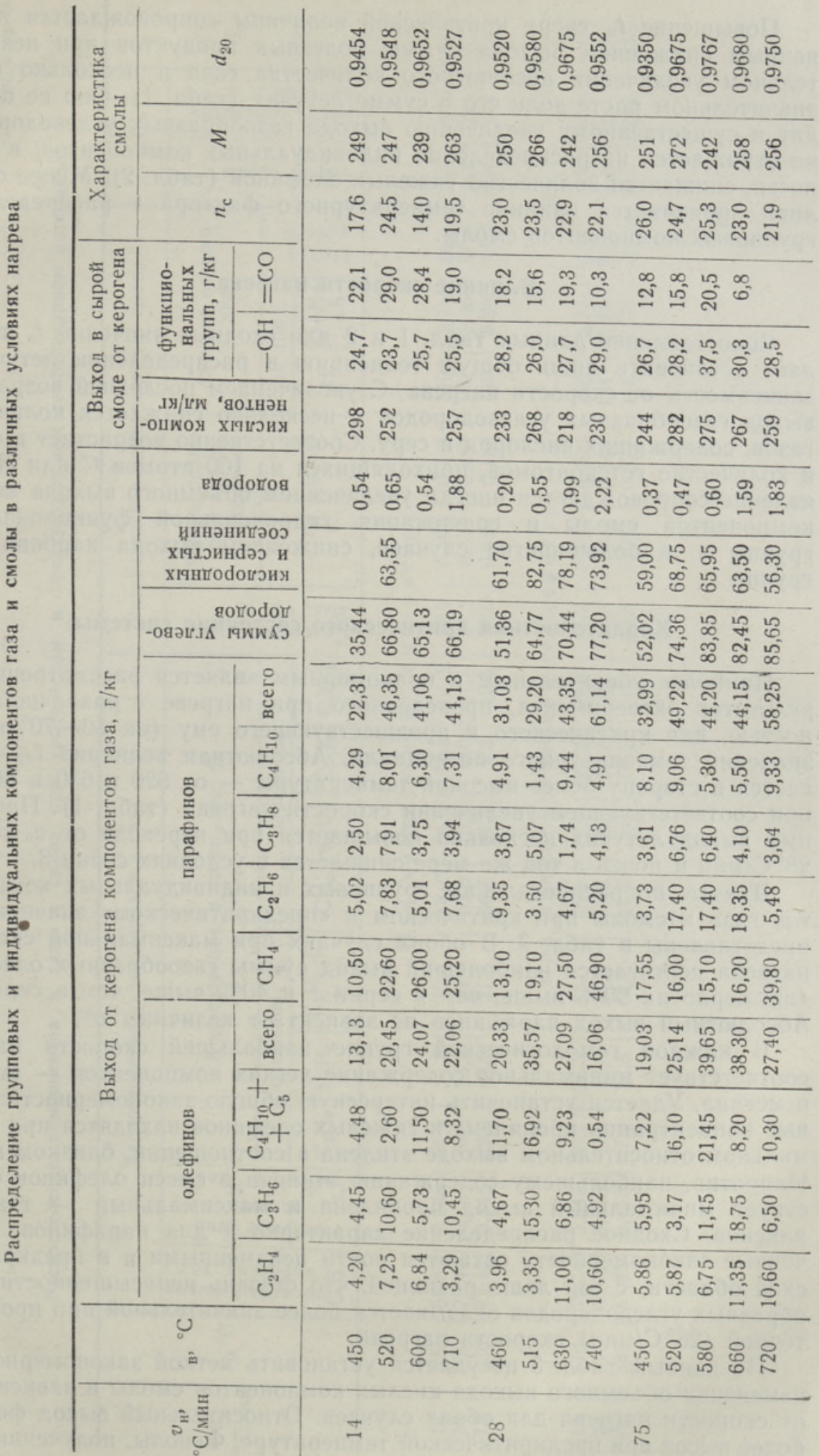


Повышение $t_{\mathrm{B}}$ сверх критической величины сопровождается постепенным снижением выхода суммы полезных продуктов при незначительном увеличении абсолютного количества газа и несколько более значительном росте доли его в сумме летучих (табл. 1). Оно не приводит к существенному увеличению выхода газообразных углеводородов, но отражается на распределении индивидуальных компонентов; в частности, снижается количество тяжелых олефинов (табл. 2). Менее отчетливо проявляется влияние температурного фактора в распределении групповых компонентов смолы.

\section{Влияние скорости нагрева}

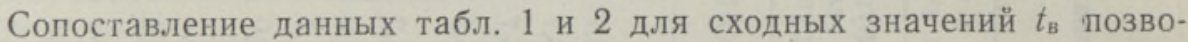
ляет установить лишь общую тенденцию в распределении летучих в зависимости от скорости нагрева. С увеличением последней возрастает выход газообразных углеводородов и несколько снижается количество газов, содержащих кислород и серу. Соответственно возрастает в смоле и количество гетероатомов, приходящихся на 100 атомов С или Н. Это явление сопровождается иногда увеличением объемного выхода кислых компонентов смолы и содержания гидроксильной функциональной группы и, в большинстве случаев, снижением выхода карбонильной группы.

\section{Характеристика критического состояния системы}

Наиболее убедительным и правомерным является рассмотрение результатов эксперимента, проведенного при нагреве с различной скоростью, для критического и предшествующего ему (на $50-70^{\circ}$ ниже) значений температурного потенциала. Абсолютная величина $t_{\text {кр }}$ сдвигается в сторону более высокой температуры - от 520 к 630 и $660^{\circ}-$ при соответствующем увеличении скорости нагрева (табл. 1). Предельный выход летучих несколько повышается при переходе от $v_{\text {н }}=14 \mathrm{k}$ $28^{\circ} \mathrm{C} /$ мнн и почти в той же мере снижается в условиях серии 3.

Данные по распределению групповых и индивидуальных компонентов газа и смолы при критическом и «предкритическом» значениях $t_{\mathrm{B}}$ представлены в табл. 3. В обоих случаях при максимальной скорости нагрева достигается наибольший выход суммы газообразных олефинов (примерно на $90 \%$ выше, чем в серии 1 и $40 \%$ выше, чем в серии 2). Абсолютный выход парафинов не зависит от величины $v^{\text {म }}$.

В каждой гомологической группе наибольшей скорости нагрева соответствует минимальное содержание легких компонентов - этилена и метана. Удается установить интересную общую закономерность: весовые концентрации пропилена и тяжелых олефинов находятся при минимальном относительном выходе этилена в соотношении, близком к $2: 1$. Напротив, наибольшему содержанию этилена в смеси олефинов сопутствует минимальный выход пропилена и максимальный - тяжелых алкенов. Сходное распределение характерно и для парафинов. Отмеченные закономерности остаются почти неизменными и в предкритической области, с той лишь разницей, что степень ненасыщенности газообразных углеводородов оказывается более значительной при промежуточной $\left(28^{\circ} \mathrm{C} /\right.$ мин) скорости нагрева.

По данным табл. 3 не удается установить четкой закономерности в изменении объемного выхода кислых компонентов смолы в зависимости от скорости нагрева для обоих случаев. Относительный выход фенолов более высок при предкритической температуре. Фенолы, полученные при 


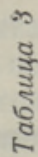

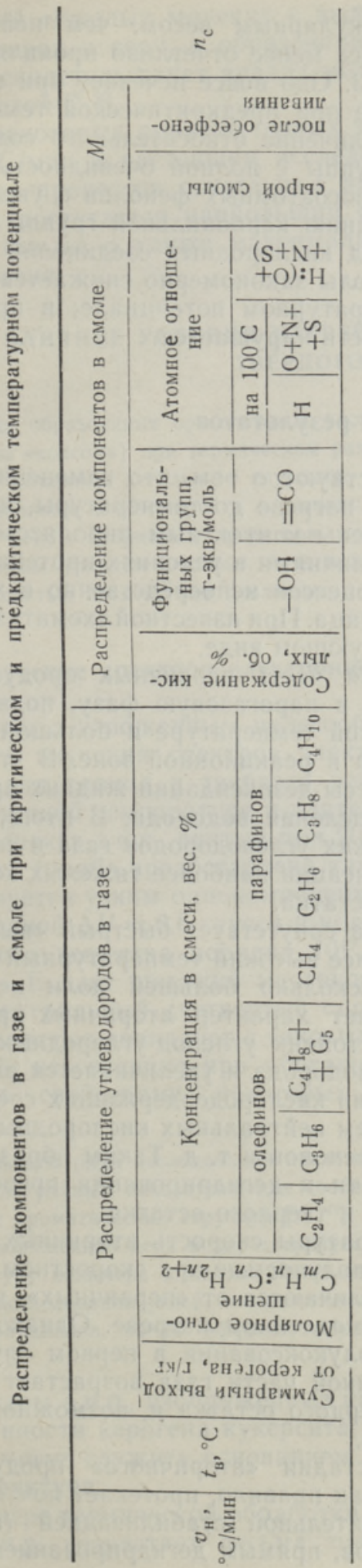

$\operatorname{lng} 0$

C. 10

సัNָ

กิ กิบ

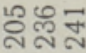

유워

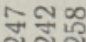

$\infty 00 \frac{1}{1}$

$0 \infty \forall$

กัN

NนคO

సั

ㅁํㅇ

เि

RNO

เก็ก

ํํำำำำ

คุำ 퓨

तूo

- m요

000 त 000

$-N$.

लें क्ले

2

mor

$m \pi$

nin

=ㅇํㅇ

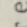

(2)

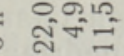

$=0 \%$

mก

काர்

()

$=0 \times 2$

$=00 \underline{7}$

a

4

$=$ +

ㅇ․

二

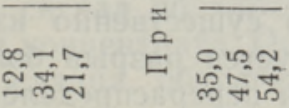

$\infty m$

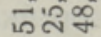

mon

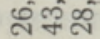

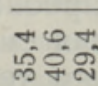

N.2.

$\infty$ का

윰ำ

m.5

돘응

लिए

$\therefore$ ㄴ?

落被

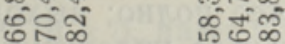

ิํㅇㅇㅠ 윰요

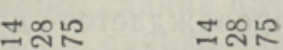


$t_{\text {кр }}$ обладают более высоким молекулярным весом, чем нейтральные компоненты смолы. Это различие все менее отчетливо проявляется при переходе от серии 1 к сериям 2 и 3 . Оно вовсе исчезает при нагреве с наибольшей скоростью и выдержке при предкритической температуре. Закономерное в обоих случаях увеличение относительного содержания гидроксильной функциональной группы с полной очевидностью свидетельствует о повышении выхода многоатомных фенолов с увеличением скорости нагрева. Судя по содержанию карбонильной группы в смоле, есть основания полагать, что выход кислородных соединений в общей массе нейтральных компонентов смолы закономерно снижается с увеличением $v_{\text {н }}$ при критическом температурном потенциале; в предкритической же области эта закономерность нарушается.

\section{Обсуждение результатов}

Приведенные данные свидетельствуют о том, что изменения в распределении летучих продуктов при нагреве до температуры, не превышающей критическую, не обусловлены контактным пиролизом парогазовой смеси. Они определяются различиями в условиях протекания первичного и, особенно, вторичных процессов непосредственно в ходе термического разложения керогена сланца. При известной схематизации эти различия можно представить в следующем виде.

При медленном нагреве основная часть первичных продуктов деструкции керогена, не перешедшая в парогазовую фазу, подвергается разложению при сравнительно низкой температуре и большой продолжительности пребывания материала в реакционной зоне. В этих условиях преобладают вторичные процессы дезоксидации жидких продуктов и внутримолекулярного перераспределения водорода. В итоге, степень ненасыщенности выделяющихся легких углеводородов газа и смолы невелика, так же как и степень конденсации наиболее тяжелых компонентов смолы и уплотнения твердого остатка.

Увеличению же скорости нагрева сопутствует быстрый «выход» системы на заданный относительно более высокий температурный уровень. Это обеспечнвает дистилляцию несколько большей доли первичных продуктов, но существенно изменяет характер вторичных процессов. Интенсифицируется разрыв более стойких углерод-углеродных связей; ограничивается перераспределение водорода и увеличивается выход непредельных; происходит стабилизация кислородсодержащих соединений в смоле с разрушением и уплотнением нейтральных кислородных соединений, сохранением более стойких фенолов и т. д. Таким образом, процессы одновременной декарбонизации и дегидрирования преобладают над реакциями дезоксидации смолы и твердого остатка.

Поскольку с повышением температуры скорость вторичных процессов возрастает весьма значительно, получаемые при скоростном нагреве летучие вещества не менее резко отличаются от «первичных», чем продукты разложения керогена при замедленном нагреве. Однако, потенциальные возможности процесса полукоксования в первом случае используются более полно; выход ценной части газа возрастает за счет более значительного уплотнения твердого остатка и, возможно, компонентов высококипящей части смолы.

Разложение в заключительной стадии «вторичного» продукта уплотненных тяжелых молекул, - как правило, протекает почти одинаково. Оно сопровождается дополнительной стабилизацией (насыщением) образующихся легких осколков, прямым дегидрированием и дез- 
оксидацией тяжелых молекул с выделением водорода, газов, содержащих кислород и серу, и образованием сильно уплотненного кокса. Об этом же свидетельствует анализ экспериментальных данных других исследователей $\left[{ }^{8,9}\right]$.

При некоторых промежуточных значениях скорости нагрева (например, $28^{\circ} \mathrm{C} /$ мин в настоящем исследовании) оба описанных выше типа вторичных процессов сочетаются примерно в равной степени. В этих условиях достигается наибольший суммарный выход летучих и, в частности, смолы, а также максимальная степень полезного использования керогена.

\section{ВЛИЯНИЕ УСЛОВИИ НАГРЕВА НА ВЫХОД И СТРУКТУРУ ТВЕРДОГО ОСТАТКА}

Процесс образования органической части твердого остатка (условно именуемой в дальнейшем «коксом») при термическом разложении кукерсита до настоящего времени не служил объектом детального изучения. На основании изложенных выше результатов исследования можно прийти к выводу, что формирование кокса непосредственно связано с ходом вторичных процессов; его характер и интенсивность определяются энергетическим уровнем системы, т. е. величиной температурного потенциала и продолжительностью воздействия последнего.

\section{Изучение спектров электронного парамагнитного резонанса}

В связи с изложенным целесообразно рассмотреть результаты проведенного изучения спектров электронного парамагнитного резонанса (э.п.р.) для сланца и твердого остатка его термического разложения при различной температуре и длительности выдержки. На фиг. 1 а представлен спектр э.п.р., снятый при $20^{\circ} \mathrm{C}$ для обогащенного до $O^{\mathfrak{c}}=89,9 \%$ кукерсита (проба предоставлена канд. техн. наук А. С. Фоминой); он характеризуется узким однокомпонентным сигналом с фактором $g=2,002$, полушириной $\Delta H=0,6$ гаусса и количеством неспаренных спинов на 1 г изучаемого вешества порядка $10^{17}$. Исходная проба сланца из смеси слоев A-E дает широкий многокомпонентный спектр (фиг. 1б), в котором центральный (четвертый справа) сигнал по характеру и структуре полностью совпадает с таковым для концентрата. Остальные шесть сигналов, исчезающие при обогащении сланца, обусловлены парамагнитными свойствами некоторых компонентов минеральной части сланца,

Результаты ряда исследований показывают, что однокомпонентный узкий сигнал с g-фактором, равным показателю для свободного электрона, характерен для полисопряженных и ароматических структур $\left[{ }^{10},{ }^{11}\right]$. Интенсивность такого сигнала определяется длиной сопряженной цепи и характеризует свойства молекулы изучаемого вещества, а не структуру полимера в целом. Узкие однокомпонентные сигналы э.п.р., обнаруженные при исследовании углей, соответственно свидетельствуют не о наличии в них свободных радикалов, но об эффекте, обусловленном системой полисопряженных связей $\left[{ }^{10}, 166\right]$.

Спектры э.п.р., изображенные на фиг. $1 a$ и 6 , дают представление об уплотненности керогена кукерсита, однако без специального исследования не могут служить основанием для точного суждения о его химической структуре.

По мере термической обработки исходного сланца интенсивность сигнала э.п.р. визрастает весьма значительно, однако структура его во 
всем изученном диапазоне значений $t_{\text {в }}$ и $\tau_{\text {в }}$ остается неизменной. В качестве примера на фиг. 18 приведен характерный спектр э.п.р., снятый при $20^{\circ} \mathrm{C}$ для сланца, подвергнутого термическому разложению при $360^{\circ}$ с выдержкой в течение 60 мин.
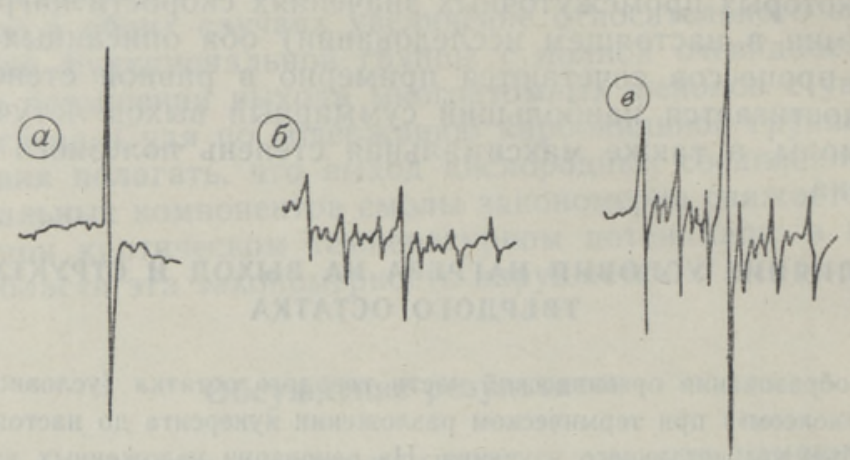

Фиг. 1. Спектры электронного парамагнитного резонанса в образцах сланца-кукерсита: $a$ - обогащенный кукерсит (концентрат); 6 - смесь сланца из слоев А - Е; $\boldsymbol{\theta}$ - термически обработанный сланец $\left(t_{\mathrm{s}}=360^{\circ}, \tau_{\mathrm{s}}=60\right.$ мин $)$.

В табл. 4 представлены основные результаты исследования образцов твердого материала, а в табл. 5 - битумов, полученных из образцов № 6-8. Интенсивность сигналов э.п.р. в обоих случаях выражена в условных единицах.

На фиг. 2 приведена зависимость интенсивности сигнала э.п.р. $I$ и удельного электросопротивления @ для исследуемых образцов от тем-

таблица 4

Основные результаты изучения спектров э.п.р. для твердого материала $\left(v_{\mathrm{H}}=14^{\circ} \mathrm{C} /\right.$ мин $)$

\begin{tabular}{|c|c|c|c|c|c|c|c|c|}
\hline \multirow{2}{*}{ 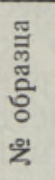 } & \multirow[b]{2}{*}{$\begin{array}{c}\text { Наименование } \\
\text { материала }\end{array}$} & \multirow[b]{2}{*}{$t_{\mathrm{B}},{ }^{\circ} \mathrm{C}$} & \multirow[b]{2}{*}{$\begin{array}{c}\tau_{\mathrm{B}}, \\
\text { мин. }\end{array}$} & \multicolumn{3}{|c|}{ Выход от керогена, \% } & \multirow[b]{2}{*}{$I$} & \multirow[b]{2}{*}{$\begin{array}{c}\text { Удельное } \\
\text { электро- } \\
\text { сопротивле- } \\
\text { ние, ом•см** }\end{array}$} \\
\hline & & & & $\begin{array}{l}\text { суммы } \\
\text { летучих }\end{array}$ & остатка & $\begin{array}{c}\text { битума } \\
\text { (в остат- } \\
\text { ке) }\end{array}$ & & \\
\hline & $\begin{array}{l}\text { Исходный сла- } \\
\text { нец }\end{array}$ & & & & 100,0 & & & $2,3 \cdot 10^{8}$ \\
\hline $\begin{array}{r}5 \\
6 \\
7 \\
8 \\
9 \\
10 \\
11 \\
12 \\
13 \\
14 \\
15 \\
16\end{array}$ & $\begin{array}{c}\text { Термически об- } \\
\text { работанный } \\
\text { сланец }\end{array}$ & $\begin{array}{l}280 \\
360 \\
380 \\
420 \\
430 \\
450 \\
450 \\
450 \\
475 \\
475 \\
520 \\
520\end{array}$ & $\begin{array}{r}120 \\
60 \\
30 \\
20 \\
20 \\
0 \\
15 \\
30 \\
0 \\
15 \\
0 \\
15\end{array}$ & $\begin{array}{l}20,3 \\
19,5 \\
41,7 \\
41,7 \\
49,5 \\
57,7 \\
67,5 \\
68,8 \\
75,0 \\
78,4 \\
82,9\end{array}$ & $\begin{array}{l}79,7 \\
80,5 \\
58,3 \\
58,3 \\
50,5 \\
42,3 \\
32,5 \\
31,2 \\
25,0 \\
21,6 \\
17,1\end{array}$ & $\begin{array}{l}5,3^{*} \\
0^{*}\end{array}$ & \begin{tabular}{c|}
25 \\
42 \\
43,5 \\
136,5 \\
118 \\
99 \\
108 \\
162 \\
129,5 \\
193 \\
207 \\
216
\end{tabular} & $\begin{array}{l}5,5 \cdot 10^{10} \\
2,0 \cdot 10^{10} \\
1,6 \cdot 10^{10} \\
1,8 \cdot 10^{10} \\
5,1 \cdot 10^{10} \\
4,7 \cdot 10^{10} \\
4,2 \cdot 10^{10} \\
3,6 \cdot 10^{10} \\
2,6 \cdot 10^{10} \\
2,2 \cdot 10^{10} \\
3,4 \cdot 10^{9} \\
5,3 \cdot 10^{8}\end{array}$ \\
\hline
\end{tabular}

* Определено путем обработки данных из работ $[8,12,13]$.

** Постоянный ток, $U=500$ вольт. 
пературы выдержки при практически неизменном значении $\tau_{\mathrm{B}}$ (ввиду резкого различия в скорости суммарной реакции разложения небольшие отклонения от величины $\tau_{\text {в }} \cong 15$ мин не могут иметь существенного значения). По кривой 1 фиг. 2 можно заключить, что с повышением $t_{\text {в }}$ сравнительная интенсивность сигнала э.п.р. (характеризующая, как указано выше, длину цепи и количество сопряженных связей) имеет тенденцию к существенному росту. Наблюдаемые перегибы кривой 1 в точках, соответствующих $t_{\text {в }} \approx 430$ и $450^{\circ}$, объясняются значительным содержанием в пературы материале термобитума, которому свойственна, как это видно

Таблица 5

Результаты исследования термобитумов

\begin{tabular}{|c|c|c|c|c|c|c|c|}
\hline \multirow{2}{*}{ 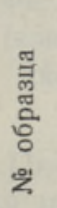 } & \multicolumn{2}{|c|}{$\begin{array}{c}\text { Условия по- } \\
\text { лучения би- } \\
\text { тума }\end{array}$} & \multicolumn{2}{|c|}{$\begin{array}{l}\text { Выход от } \\
\text { керогена, } \\
\text { вес. \% }\end{array}$} & \multirow{2}{*}{$n_{\mathrm{c}}$} & \multirow{2}{*}{$M$} & \multirow{2}{*}{$I$} \\
\hline & $t_{\mathrm{B}},{ }^{\circ} \mathrm{C}$ & $\begin{array}{c}\tau_{\mathrm{B}}, \\
\text { мин. }\end{array}$ & $\begin{array}{l}\text { лету- } \\
\text { чих }\end{array}$ & $\begin{array}{c}\text { биту- } \\
\text { ма }\end{array}$ & & & \\
\hline $\begin{array}{l}20 \\
21 \\
22\end{array}$ & $\begin{array}{l}360 \\
380 \\
420\end{array}$ & $\begin{array}{l}60 \\
30 \\
20\end{array}$ & $\begin{array}{l}20,3 \\
19,5 \\
41,7\end{array}$ & $\begin{array}{l}33,2^{*} \\
69,9^{*} \\
33,2\end{array}$ & $\begin{array}{l}23,5 \\
27,0 \\
30,0\end{array}$ & $\begin{array}{l}770 * \\
920 * \\
750\end{array}$ & $\begin{array}{r}3,5 \\
5,0 \\
30,5\end{array}$ \\
\hline
\end{tabular}

* По литературным данным для сходных условнй $[12,13]$.

из табл. 5 , небольшая, по сравнению с суммарным твердым остатком, интенсивность сигнала э.п.р. Антибатфиг. 2 на основном участке представляет собой обычное явление для ряда полисопряженных систем [10, 11].

На основании данможно заключить, что активное коксообразование имеет место уже при $420^{\circ}$, начало же ность кривых 1 и 2 ных табл. 4 и фиг. 2 этого процесса для данной скорости нагрева следует отнести ориентировочно к $400^{\circ}$. Сопоставление значений $I$ для образцов № $10-12,13-14$ и $15-16$ позволяет судить о кинетике коксообразования при температурах 450 , 475 и $520^{\circ}$. Целесообразно сравнить между собой показатели для указанных температурных ступеней. В первых двух случаях длительность выдержки существенно отражается на величине $I$. При $475^{\circ}$ и $\tau_{\text {в }}=$ $=15$ мин последняя значительно выше, чем у образца № 12 (соответственно 193 и 162). Уплотненность же кокса при $t_{\mathrm{B}}=520^{\circ}$ и $\tau_{\mathrm{s}}=0$ еще выше $(I=207)$ и лишь незначительно возрастает в результате пятнадцатиминутной выдержки (до $I=216$ ).

Более детальное ознакомление с данными табл. 5 свидетельствует о небольшом, но совершенно очевидном увеличении интенсивности сигнала э.п.р. (для битумов) уже при переходе от $t_{\mathrm{s}}=360 \mathrm{\kappa} 380^{c}$ (образцы № 20-21) и более значительном росте при $420^{\circ}$. Это наблюдается непосредственно подтверждает высказанное ранее утверждение о развнтии вторичных процессов даже в низкотемпературной области и значительной их активизации при температуре, соответствующей началу интенсивного выделения летучих. 


\section{Динамика образования и изменения структурных свойств кокса}

Одним из эффективных способов оценки количественных и качественных превращений при деструкции полимеров и термическом разложении твердых топлив является изучение их структурно-физических свойств [14,15]. Ниже излагаются результаты такого исследования применительно к твердому остатку термического разложения кукерсита из опытов серий $1-3$.

В качестве критериев оценки количественных и структурных изменений в сланце под влиянием нагрева приняты: коэффициент сопротивления $\Pi$, характеризующий механическую прочность системы при дроблении в результате воздействия ударной нагрузки $\left[{ }^{34}\right]$, и коэффициент пористости $m$, определяемый обычным способом по соотношению истинного и кажущегося удельного веса материала и связанный с изменением структуры твердого остатка не только вследствие выделения летучих, но и формирования кокса $\left.{ }^{15}\right]$.

В табл. 6 приведены в сокращенном виде основные результаты проведенных исследований. В нее включены также данные, характеризующие выход и состав органической части твердого остатка и имеющие непосредственное практическое значение сведения о выходе тонкой пыли в результате механического воздействия на материал. На фиг. $3 a$, 6 и $в$ представлены кривые изменения значений $m$ и $\Pi$ в зависимости от температуры выдержки при указанных выше различных скоростях нагрева.

Таблица 6

Влияние условий нагрева на выход и структуру твердого остатка

\begin{tabular}{|c|c|c|c|c|c|c|c|}
\hline$t_{\mathrm{B}},{ }^{\circ} \mathrm{C}$ & $\begin{array}{c}\text { Выход кокса } \\
\text { от керогена, } \\
\text { вес. } \%\end{array}$ & $\begin{array}{l}\text { Отноше- } \\
\text { ние C:H } \\
\text { в коксе }\end{array}$ & $m$ & $\%$ & $\Pi, \mathrm{r} / \mathrm{cm}$ & $\begin{array}{l}\text { Выход } \\
\text { пыли, } \\
\text { вес. \% }\end{array}$ & $\begin{array}{c}\text { Степень раз- } \\
\text { ложения } \\
\text { карбонатов, } \\
\%\end{array}$ \\
\hline
\end{tabular}

Серия 1. Скорость нагрева $14 \%$ мин

\begin{tabular}{l|l|r|r|r|r|r}
450 & 15,7 & 11,9 & 60,5 & 100,1 & 6,22 & \\
470 & 14,5 & 12,2 & 65,5 & 81,3 & 11,26 & \\
520 & 12,6 & 13,8 & 74,5 & 100,8 & 7,47 & \\
600 & 12,8 & & 61,0 & 137,9 & 6,34 & \\
710 & 13,0 & & 67,3 & 89,0 & 9,94 & 18,7 \\
800 & $12,1^{*}$ & & 73,3 & 80,0 & 12,92 & 74,3
\end{tabular}

Серия 2. Скорость нагрев а $28 \%$ мин

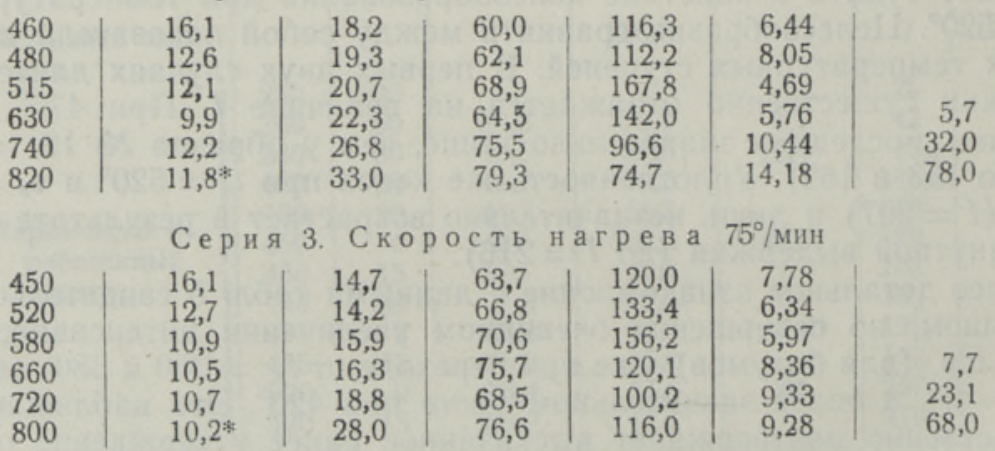

* Снижение выхода кокса при $t_{\mathrm{B}} \approx 800^{\circ}$ является результатом поддающегося учету расхода углерода на восстановление углекислого газа. 
Характер всех трех кривых типа 1 фиг. $3 m=f\left(t_{\mathrm{B}}\right)$ идентичен. Рост пористости с повышением температуры по достижении некоторого максимума сменяется спадом, а затем вторичным подъемом каждой кривой. Сходная закономерность была обнаружена и другими исследователями при нагреве кукерсита со значительно меньшей скоростью - в среднем около $3,5^{\circ} \mathrm{C} /$ мин $\left.{ }^{16}\right]$. При этом первый максимум пористости, обусловленный активным выделением летучих после перехода подавляющей части органического вещества в пластическое состояние, соответствовал температуре $440^{\circ}$ и выходу летучих около $78 \%$ от керогена (т. е. примерно $85 \%$ от предельного).
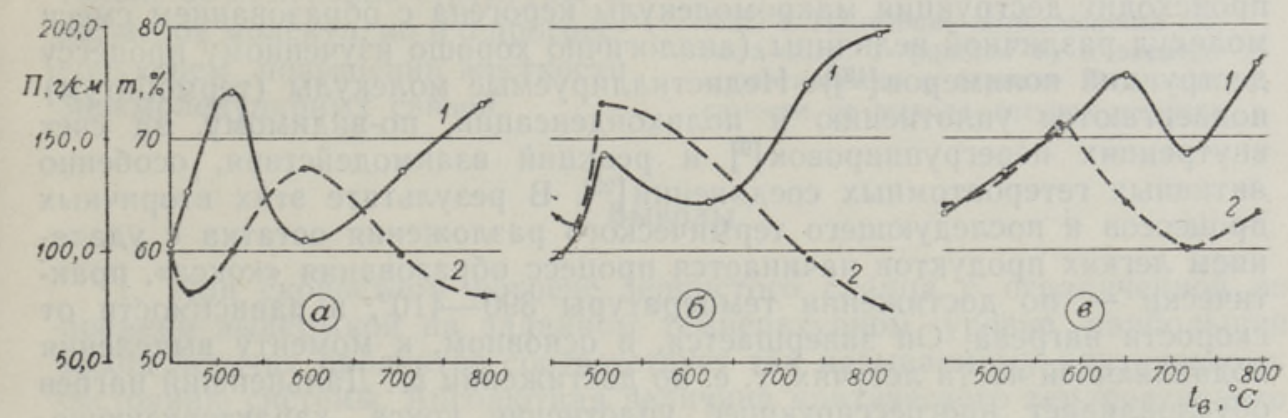

Фиг. 3. Изменение пористости $m$ (кривая 1 ) и коэффициента сопротивления $\Pi$ (кривая 2) в зависимости от температуры изотермйческой выдержки $t_{\mathrm{B}}$ прн скорости нагрева, равной: $a-14^{\circ} \mathrm{C} /$ мин; $\sigma-28^{\circ} \mathrm{C} /$ мин; $в-75{ }^{\circ} \mathrm{C} /$ мин,

По данным табл. 6 и кривых фиг. 3 , температура $t_{\mathrm{n}}$, соответствующая первому максимуму $m$, повышается по мере увеличения скорости нагрева от $520^{\circ}$ в серии 1 до $660^{\circ}$ в серии 3 . Описанные изменения вполне закономерны, так как с увеличением скорости нагрева температур. ные пределы активного выделения летучих, так же как и пластического состояния сланца, несколько растягиваются и сдвигаются в сторону более высоких значений $\left[{ }^{17,18}\right]$.

Анализ кривых типа 1 фиг. 3 , равно как и литературных данных $\left[{ }^{15}, 18\right]$, свидетельствует о наличии усадки на известной стадии нагрева кукерсита, соответствующей почти предельному (85-88\% от керогена) выделению летучих и формированию более жесткой структуры кокса [15]. Для температуры максимальной усадки - $t_{y}-$ с увеличением скорости нагрева также наблюдается соответствующий сдвиг в сторону более высоких значений. Характерным для кукерсита является постоянство разности значений $t_{\mathrm{y}}$ и $t_{\mathrm{n}}$ для каждой данной скорости нагрева в диапазоне $v_{\text {н }}$ от 3,5 до $75^{\circ} \mathrm{C} /$ мин

$$
t_{\mathrm{y}}-t_{\mathrm{n}} \cong 80^{\circ} \mathrm{C} \text {. }
$$

На основе приведенных данных можно установить четкую зависимость между скоростью нагрева (в указанных пределах значений $v_{\text {н }}$ ) и температурой выдержки, соответствующей максимальным пористости и усадке твердого остатка:

$$
t_{\mathrm{y}}=552 e^{0,0041 v_{\mathrm{H}}} ; \quad t_{\mathrm{n}}=456 e^{0,0055 v_{\mathrm{H}}} .
$$

Рассмотрение кривых типа 2 фиг. $3 \Pi=f\left(t_{\mathrm{B}}\right)$ показывает, что пористость материала не может однозначно характеризовать происходящие 
количественные и структурные изменения. Прочность твердого остатка во всех трех сериях опытов оказывается минимальной при температуре активного выделения летучих $450-475^{\circ}$. В остальном же характер изменения $\Pi$ не всегда соответствует видимому изменению макроструктуры твердого остатка. Аналогичное явление наблюдается и при коксовании углей $\left[{ }^{15}\right]$. В настоящем случае это связано не только с условиями формирования кокса, но и (при повышенных температурах) с разложением компонентов минеральной части, в частности - при нагрезе с различной скоростью.

Динамика коксообразования в упрощенном виде может быть представлена следующей схемой. При сравнительно невысокой температуре происходит деструкция макромолекулы керогена с образованием смеси молекул различной величины (аналогично хорошо изученному процессу деструкции полимеров $\left.\left[{ }^{19}\right]\right)$. Недистиллируемые молекулы (термобитум) подвергаются уплотнению и поликонденсации, по-видимому, за счет внутренних перегруппировок $\left.{ }^{9}\right]$ и реакций взаимодействия, особенно активных гетероатомных соединений $\left[{ }^{20}\right]$. В результате этих вторичных процессов и последующего термического разложения остатка с удалением легких продуктов начинается процесс образования «кокса», практически - по достижении температуры $390-410^{\circ}$, в завискимости от скорости нагрева. Он завершается, в основном, к моменту выделения подавляющей части летучих, т. е. по достижении $t_{n}$. Дальнейший нагрев обусловливает прогрессирующее уплотнение кокса, характеризующегося более жесткой структурой и усадкой. В реальных условиях указанные процессы не могут быть четко разграничены и зачастую накладываются друг на друга.

Поскольку скорость и глубина вторичных реакций значительно возрастают с температурой, при повышенной скорости нагрева кокс формируется в более жестких условиях, чем продукт разложения при медленном нагреве, и должен обладать большей механической прочностью. Обработка приведенных в статье данных и результатов других исследований $\left[{ }^{8,12}\right]$ позволяет иллюстрировать это утверждение ориентировочными расчетами. В этих расчетах принято, что соотношение количества выделившихся летучих и кокса близко к постоянному в пределах от $400^{\circ}$ и кончая $t_{\text {п }}$.

Для примера приводятся результаты расчета при $t_{\mathrm{B}}=450^{\circ}$ и $v_{\mathrm{H}}=14^{\circ} \mathrm{C} / \mathrm{мин}$; около $43 \%$ кокса образуется при неизотермическом нагреве, в пределах от 400 до $450^{\circ}$, и примерно 57\% - при предельной постоянной температуре. В случае нагрева со скоростью $75^{\circ} \mathrm{C} /$ мин в низкотемпературной области выделяется не более $28 \%$ кокса, при $t_{\mathrm{B}}=450^{\circ}-$ свыше $70 \%$. Значения $\Pi$ в опытах серий 1 и 3 с выдержкой при этой температуре составляют соответственно 100 и $120 \mathrm{r} / \mathrm{cm}$.

Продукт из серии 2 занимает промежуточное положение.

В известных условиях уменьшение пористости при усадке (возрастающее с повышением температуры до $t_{\mathrm{s}}=t_{\mathrm{y}}$ ) не компенсирует возникающих в материале внутренних напряжений и механическая прочность его снижается. Величина $\Pi$ особенно резко уменьшается при наибольшей усадке, например, $630^{\circ}$ для серии 2 и $720^{\circ}$ для серии 3 . Исключение составляет серия 1, в которой при максимальной усадке выход кокса относительно велик, а жесткость межмолекулярных связей и обусловленная ею хрупкость сравнительно малы.

Изложенные представления находят подтверждение и при анализе кривых фиг. 4, построенных для образцов серии 4, практически не со- 
держащих термобитума. При увеличении выхода летучих сверх $78 \%$ от керогена темп роста $I$ (кривая 1), отражающий наращивание длины полисопряженных молекул, снижается. Соответствующее же резкое увеличение электропроводности материала - почти на два порядка (кривая 2) - свидетельствует не только об изменении структуры и размеров молекул, но и о прогрессирующем повышении жесткости межмолекулярных связей.

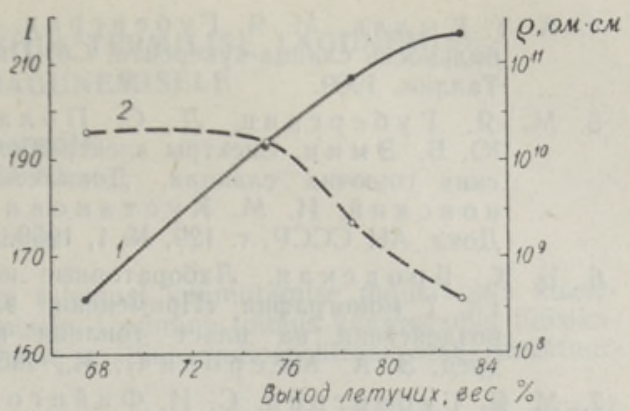

Фиг. 4. Изменение интенсивности сигнала э.п.р. I (кривая 1 ) и электросопротивления @ (кривая 2) в зависимости от выхода летучих веществ.

\section{Выводы}

1. При скоростном нагреве зернистого сланца с ограниченной во времени выдержкой на заданном температурном уровне наибольший выход летучих продуктов соответствует так называемому критическому состоянию системы. Абсолютная величина критического температурного потенциала возрастает с увеличением скорости нагрева.

2. Распределение и выход групповых и индивидуальных компонентов газа и смолы можно гибко регулировать путем подбора соответствующих скорости нагрева и температуры выдержки. Выход органической части твердого остатка и модификация структурно-физических свойств последнего находятся в тесной связи с динамикой вылеления летучих и коксообразования, а также с условиями нагрева.

3. Формирование летучих и кокса в значительной степени определяется условиями и интенсивностью протекания вторичных процессов при термическом разложении сланца. Перспективным путем дальнейпиих исследований является разработка методов активированной деструкции керогена кукерсита при сравнительно низкой температуре с ограничением вторичных процессов.

4. В условиях скоростного полукоксования зернистого сланца с твердым теплоносителем (скорость нагрева $25-30^{\circ} \mathrm{C} / \mathrm{Mин}$ ) оптимальным является «предкритический» температурный потенциал 515-520. При этом обеспечиваются: высокий общий выход летучих, рост выхода газообразных олефинов (за счет наиболее ценных для химического синтеза компонентов) и кислых соединений в смоле; повышается термомеханическая стабильность полукокса и снижается количество образующейся в реакторе тонкодисперсной пыли.

\section{ЛИТЕРАТУ РА}

1. М. Я. Губергриц, Б. Х. Бродская, Л. П. Паальме, А. А. Мильк, Влияние способа эвакуации летучих на выход и состав продуктов термического разложения сланца-кукерсита, Подземн. газиф. углей, № 4, 1959.

2. А. Я. А а рна, Э. Т. Л и п п м а а, О некоторых усовершенствованных формах графостатического метода изучения строения органических соединений, Тр. Таллинск. политехн. ин-та, Сер. А, № 63, 1955.

3. К. И. С ысков, Закономерности процесса разрушения и прочность твердых кусковых тел. Тр. ИГИ АН СССР, т. II, 1950. 
4. А. Т. Кылль, М. Я. Губергриц, Х. А. Ахерм а, Термомеханическая стабильность сланца-кукерсита, Сб. Горючие сланцы. Химия и технология, вып. 3 , Таллин, 1960.

5. М. Я. Губергриц, Л. С. Полак, Б. Х. Бродская, К. А. Куйв, Ю. Б. Э м и н, Спектры электронного парамагнитного резонанса в прибалтийских горючих сланщах, Докл. АН СССР (в печати); Ю. А. Колба новский, И. М. Кустанович, Л. С. Полак, А. С. Щербакова, Докл. АН СССР, т. 129, № 1, 1959.

6. Б. Х. Бродская, Лабораторные исследования процесса расширения канала, Гл. 7 монографии «Применение электрического тока для непосредственного воздействия на пласт топлива при бесшахтной подземной газификации» (ред. Э. А. Меерович), М., 1959.

7. М. Я. Гу бе ргриц, С. И. Файнгольд, А. А. Ми льк, Химико-технологическая характеристика процесса подземной переработки сланца, Гл. 3 монографии «Қомбинированный метод -подземной газификации сланца. Технологические основы», Таллин, 1959.

8. Э. Т. Л и п п а а, Исследование термического разложения эстонского горючего сланца, Тр. Таллинск. политехн. ин-та, Сер. А, № 97, 1958.

9. А. Я. А а рн а, Э. Т. Л и п п а а, Термическое разложение сланца-кукерсита, Тр. Таллинск. политехн. ин-та, Сер. А, № 97, 1958.

10. Н. Н. Семен о в, Коллективное взаимодействие в процессах полимеризации при низких температурах и в полимерах с сопряженными связями, Химия и технология полимеров, № $7-8,1960$, См. также:

а. Л. А. Блюмен фельд, А. А. Берлин и др., Структурная химня, т. 1, № 1, 1960, стр, 103.

б. В. В. Воеводский, Н. Н. Ти хоми ров а и др., Структурная химия, т. 1, № 1, 1960, стр. 99.

11. А. В. Топчиев, М. А. Гейдерих, Б. Э. Давыдов, В. А. К аргин, Б. А. Кренцель, И. М. Кустанович, Л. С. Полак, О возможностях получения полимерных материалов с полупроводниковыми свойствами на основе полиакрилонитрила, Докл. АН СССР, т. 128, № 2, 1959.

12. Н. Л. Луцковская, Е. И. Казаков, Комплексное термографическое и химическое исследование эстонского сланца-кукерсита, Изв. АН ЭССР. Сер. техн. и физ.-мат. наук, т. VI, № 2, 1956.

13. К. А. К аськ, О битуминизации керогена сланца-кукерсита, Тр. Таллинск. политехн. ин-та, Сер. А, № $73,1956$.

14. М. В. В олькенштейн (ред.), Сб. Физика полимеров, ИЛ, M., 1960; В. А. К аргин, Г. Л. Слоним ски й, Краткие очерки по физнко-химин полимеров, Изд. МГУ, 1960.

15. Б. А. О нус айти с, Образование и структура каменноугольного кокса, AH CCCP, M., 1960.

16. Д. К. Коллеров, Е. С. А вдонин а, Микропористость кусков горючего сланца, Тр. ВНИиПС, вып, 7, 1959.

17. Н. С. Ми и нгоф, Исследование динамики выделения летучих веществ при термическом разложении твердых топлив, Диссертация на соискание ученой степени кандидата технических наук, ИГИ АН СССР, М., 1960.

18. Я. И. В а й нш те й н, О пластическом состоянии сланца прибалтийского месторождения при его термическом разложении, Тр. ВНИИПС, вып. 3, 1955.

19. Н. Гр асси, Химия процессов деструкции полимеров, ИЛ, М., 1959.

20. В. Е. Раковский, Ф. Л. Каганович, Е. А. Новикова, Химия пирогенных процессов, Изд. АН БССР, Минск, 1959.

Институт химии

Академии наук Эстонской ССР
Поступила в редакцию 31. VIII 1960 


\title{
KUUMUTAMISE MŌJU KUKERSIIDI TERMILISE LAGUNEMISE PRODUKTIDE JAGUNEMISELE
}

\author{
M. Gubergrits, \\ tehnikakandidaat
}

Resümee

Artiklis avaldatakse kompleksse uurimise tulemusi kuumutamise mõju kohta kukersiidi termilise lagunemise produktide jagunemisele. Uurimine toimus kaasaegsetel füüsikalis-keemilistel meetoditel (gaasikromatograafiline analüüs, radiospektroskoopia, struktuursete modifikatsioonide uurimine).

Uurimisel selgus, et igale pōlevkivi kuumutamise kiirusele $14-75^{\circ} / \mathrm{min} .15$ minuti jooksul vastab oma kriitiline temperatuur, mille puhul eraldub suurim hulk lenduvaid aineid. Kriitilise temperatuuri potentsiaali absoluutne väärtus kasvab kuumutamise kiiruse kasvuga.

Gaasi ja ôli grupiliste ja individuaalsete komponentide jagunemist ja saagist ning tahke jäägi orgaanilise osa sisaldust ja omadusi on vōimalik reguleerida kuumutamise kiiruse ja kestusega. Pōlevkivi termilise lagunemise produktide moodustumine on suurel määral seoses sekundaarsete protsessidega, millede intensiivsus kasvab temperatuuri tõustes.

Põlevkivi termilisel töötlemisel tahke soojusekandjaga saavutatakse temperatuuri potentsiaali tōstmisel $515-520^{\circ}$-ni optimaalne lenduvate ainete saagis, kasvab gaasiliste olefiinide ja õli happeliste komponentide saagis ning tõuseb poolkoksi termomehhaaniline stabiilsus.

Eesti NSV Teaduste Akadeemia Keemia Instituut

Saabus toimetusse 31. VIII 1960

\section{INFLUENCE OF HEATING CONDITIONS ON THE DISTRIBUTION OF OIL SHALE THERMAL DECOMPOSITION PRODUCTS}

\section{Gubergrits}

\section{Summary}

The paper deals with the results of a complex experimental investigation, by means of modern physicochemical methods (gas chromothermography, radiospectroscopy, study of some phvsical and structural properties), of volatile matters and coke residue distribution during a high rate thermal processing of Estonian kukersite oil shale.

Each recorded rate of heating (in the interval of $14-75^{\circ} / \mathrm{C} \mathrm{min}$ ) corresponds to a critical temperature value of a 15 -min thermal exposition. The absolute value of the critical temperature grows with the increase in the rate of heating $\left(v_{\mathrm{H}}\right)$ and corresponds to the maximal yield of volatile matters.

The distribution and yield of the group and individual gas and tar components as well as the properties of the solid residue of thermal decomposition may be regulated by means of selecting a corresponding rate of heating or exposition temperature. The formation of volatile products and coke residue is highly dependent on the secondary condensing reactions which intensify with the rise of temperature.

At the thermal processing of oil shale with a solid heat carrying agent the optimal yield of volatile matters, gaseous olefin hydrocarbons and tar phenols increases, and a higher thermostability of the solid residue is achieved in the case of raising the exposition temperature to $515-520^{\circ} \mathrm{C}$. 